УДК 378.178:316.647.5

DOI 10.37386/2413-4481-2020-3-56-61

\author{
М.И. Ефанова \\ Алтайский государственный педагогический университет, г. Барнаул, Россия

\section{ВЗАИМОСВЯЗЬ СОЦИАЛЬНОГО И ЭМОЦИОНАЛЬНОГО ИНТЕЛЛЕКТА С ТОЛЕРАНТНОСТЬЮ У СТУДЕНТОВ}

\begin{abstract}
В статье приводится анализ проблемы развития эмоционального и социального интеллекта студентов. Рассматривается проблема взаимосвязи социального и эмоционального интеллекта с толерантностью. Приводятся данные о специфике взаимосвязи между толерантностью и социальным, эмоциональным интеллектом студентов.

Ключевые слова: эмоциональный интеллект, социальный интеллект, толерантность.
\end{abstract}

\author{
M.I. Efanova
}

Altai State Pedagogical University, Barnaul, Russia

\title{
THE RELATIONSHIPS BETWEEN SOCIAL, EMOTIONAL INTELLIGENCE AND TOLERANCE AMONG UNIVERSITY STUDENTS
}

\begin{abstract}
The article provides the analysis of the problem of emotional and social intelligence development among university students. The problem of interrelation between social and emotional intelligence with tolerance is considered. The article presents the data on the peculiarity of the relationships between tolerance and social and emotional intelligence of students.

Key words: emotional intelligence, social intelligence, tolerance.
\end{abstract}

Профессиональное становление будущих педагогов-психологов предполагает не только формирование важных профессиональных навыков, а также развитие личностных черт. Профессия педагога-психолога относится к одной из пяти профессиональных сфер, а именно к профессии типа «человек - человек», а умение общаться и активно взаимодействовать с людьми является неотъемлемой ею частью. Способности понимания своих эмоций и эмоций окружающих, умение выстроить дружеские отношения с противоположными людьми - представителями разных культур, взглядов, вероисповеданий - особенно важно для представителей профессий «человек - человек». Данные способности в психологии связывают с социальным и эмоциональным интеллектом.

Понятие «социальный интеллект» появился в литературе в начале XX века. Его появление связывают с работами Э. Торндайка. По его мнению, социальный интеллект - это «способность к пониманию и управлению людьми, способность действовать мудро в межличностных отношениях» [цит. по: 1]. В дальнейшем содержание и развитие понятия «социальный интеллект» расширялось за счет исследований в этой области Г. Олпорта, Г. Айзенка, Дж. Гилфорда, который является автором надежного теста для измерения социального интеллекта $[2,3]$.
В отечественной психологии под социальным интеллектом понимается способность человека понимать и предсказывать поведение других людей в различных жизненных ситуациях, а также умение различать чувства, намерения и эмоции по их вербальным и невербальным проявлениям $[4,5]$.

Концепция эмоционального интеллекта возникла из теории социального интеллекта [6]. За последние несколько лет стал формироваться ряд разнообразных теорий эмоционального интеллекта. Теории эмоционального интеллекта делятся на смешенные модели (теория Д. Гоулмена, некогнитивная теория Р. Бар-Она) и модели способностей, которые включают в себя теории эмоционально-интеллектуальных способностей Дж. Майера, П. Сэловея, Д. Карузо [7-9].

В отечественной психологии особо известно учение об эмоциональном интеллекте, разработанное и представленное Д.В. Люсиным [10]. Вначале автор дал определение эмоциональному интеллекту как способности к пониманию и управлению своими и чужими эмоциями. Умение понимать эмоции означает, что человек способен определить факт наличия эмоционального переживания у себя или у другого человека; может отождествлять эмоции, т. е. определить, какую именно эмоцию ощущает он сам или другой чело- 
век, обосновать ее словесно; понимает первопричины, вызвавшие данную эмоцию, и последствия, к которым она приведет. Возможность управления эмоциями предполагает, что человек может производить контроль над интенсивностью эмоций, первоначально приглушать излишне сильные эмоции; может контролировать внешние проявления эмоций, а также может при потребности беспрепятственно вызвать определенную эмоцию. Следовательно, эмоциональный интеллект можно изобразить как конструкт, содержащий двойственную природу и связанный, с одной стороны, с познавательными способностями, а с другой - с личностными характеристиками.

Определение толерантности остается весьма неопределенным, нет жестко отобранных его общепризнанных характеристик, оно не дифференцировано, научно необосновано. Толерантность это многоаспектное понятие, и далеко не все эти аспекты разработаны в достаточной мере полно, считает С.К. Бондырева [11]. В зарубежной литературе толерантность изучается в контексте межличностного взаимодействия. Формирование толерантности происходит лишь при соответствующих условиях, таких как повторения, упражнения и перенос способа действия в другие ситуации, т. е. при образовании паттерна поведения (бихевиоральное направление). Представители когнитивного направления рассматривают толерантность с учетом факторов социальных установок, стереотипов и возникающего в результате когнитивного диссонанса, обусловливающего, в частности, агрессивное поведение субъекта [12]. А. Маслоу и К. Роджерс, представители экзистенциально-гуманистической психологии понимают толерантность как стремление личности к самореализации $[13,14]$.

Отечественные психологи рассматривают толерантность как отличительное свойство личности, условно возникающее при столкновении различий между субъектами взаимодействия. В работах Б.Г. Ананьева толерантность, с точки зрения социально-психологического понимания, трактуется как терпимость к отличиям и эмпатия [15]. В своих исследованиях А.Г. Асмолов говорит о том, что толерантностью наделена лишь только полноценная личность, кому присущи свои интересы и ценности, в то же время уважающая позиции других. Он понимает толерантность как некую меру, определяющую «диапазон сохранения различий популяций и общностей в изменяющейся действительности» [16]. Содержательно толерантность А.Г. Асмоловым определяется как устойчивость, терпимость и допустимое отклоне- ние. Толерантность, которая возникла в результате жизнедеятельности человека, становится особо важной ценностью для самого человека и обнаруживает себя во взаимодействии с другими людьми.

Г.У. Солдатова в своих работах обозначает толерантность «как способность в проблемных и кризисных ситуациях активно взаимодействовать с внешней средой с целью восстановления своего нервно-психического состояния, успешной адаптации, недопущения конфронтации и развития позитивных взаимоотношений с собой и окружающим миром» $[17$, с. 48$]$.

Таким образом, в работах отечественных ученых толерантность рассматривается как внутриличностная черта, которая актуализируется в процессе общения субъектов, имеющих существенные отличия. Толерантность специалиста психолого-педагогического направления, как социально-психологический феномен, выражается в профессиональном взаимодействии и определяется взаимосвязью толерантных качеств личности с социальным и эмоциональным интеллектом. Это и послужило основой нашего исследования, которое базировалось на гипотезе о взаимосвязи толерантности с социальным и эмоциональным интеллектом. В исследовании приняли участие 84 студента института психологии и педагогики (АлтГПУ) в возрасте от 18 до 25 лет.

В качестве методик исследования использовались следующие: тест «Социальный интеллект» (Дж. Гилфорд) [18], диагностика эмоционального интеллекта (Д.В. Люсин) [19], экспресс-опросник «Индекс толерантности» (Г.У. Солдатова, О.А. Кравцова, О.Е. Хухлаев, Л.А. Шайгерова) [17]. Результаты теста «Социальный интеллект» (Дж. Гилфорда) представлены на рисунке 1.

Исходя из результатов диагностики социального интеллекта, представленных на рисунке 1 , современным студентам свойственно предугадывать поступки людей, опираясь на анализ реальных ситуаций общения, предвидеть события дальнейшей ситуации, базируясь на понимании чувств, мыслей, намерений участников коммуникативных связей. Это позволяет им выстроить собственную стратегию поведения для достижения поставленных целей. Помимо этого студенты умеют правильно давать оценку состояниям, чувствам, намерениям окружающих людей по их невербальным проявлениям, мимике, позам, жестам. Студенты уделяют много внимания невербальному общению, довольно часто обращая внимание на невербальные проявления участ- 
ников коммуникации. Они характеризуются повышенной чуткостью к характеру и оттенкам человеческих взаимоотношений, что помогает им быстро и верно понимать то, что люди хотят доложить друг другу (речевую экспрессию) в контексте определенной ситуации, конкретных взаимоотношений. Студенты могут различать систему межличностных отношений в динамике. Они способны проводить анализ сложных ситуаций взаимодействия людей, постигать логику их развития, а также при включении в ситуацию коммуникации других участников могут чувствовать изменения смысла. Посредством логических умозаключений они могут достраивать неизвестные, недостающие звенья в цепи этих взаимодействий, предвидеть, как люди поведут себя в дальнейшем, а также проводить анализ причины определенного поведения.

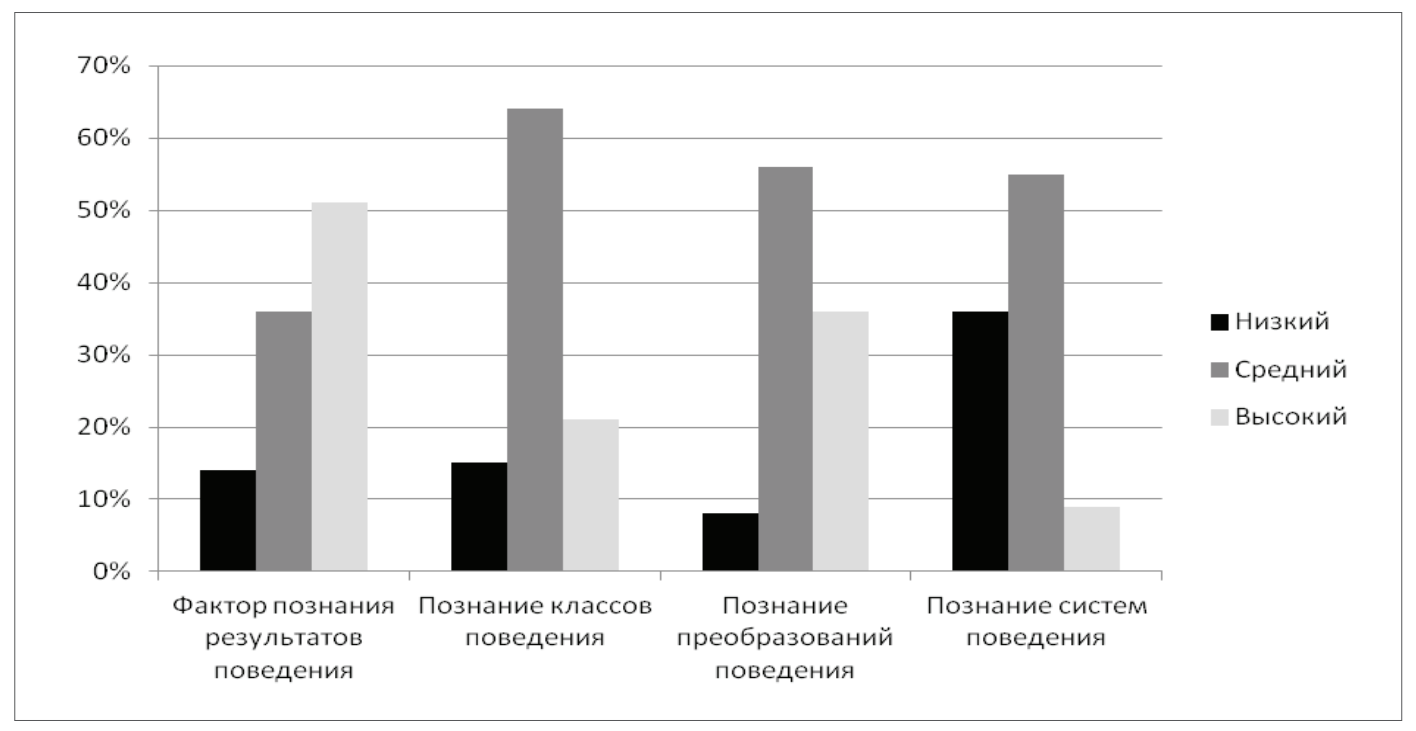

Рис. 1. Социальный интеллект (Дж. Гилфорд), \%

Студентам характерны контактность, открытость, тактичность, корректность, доброжелательность и сердечность, стремление к психологической близости в общении. Они извлекают максимум информации о поведении людей, понимают язык невербального общения, высказывают быстрые и точные суждения о людях, успешно прогнозируют их реакции в заданных ситуациях, проявляют дальновидность в отношениях с другими, что благоприятно сказывается на их социальной адаптации.

Данные по диагностике эмоционального интеллекта представлены на рисунке 2.

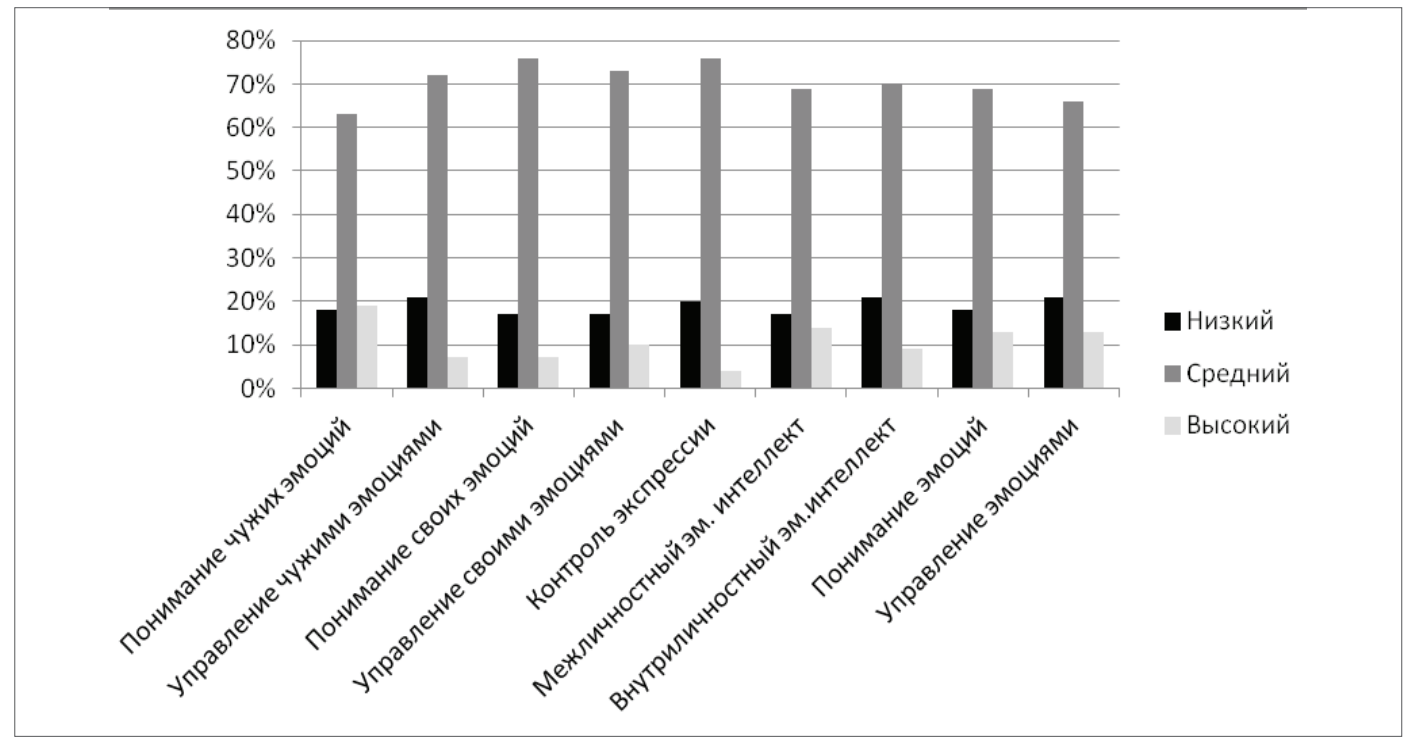

Рис. 2. Эмоциональный интеллект, \% 
Анализ эмпирических данных эмоционального интеллекта показал, что незначительное количество студентов имеют развитый эмоциональный интеллект, т. е. способны распознавать эмоциональное состояние человека, опираясь на внешние факторы, такие как проявления эмоций (мимика, жестикуляция, звучание голоса), вызывать у других людей те или иные эмоции, снижать интенсивность нежелательных эмоций, распознавать, управлять и осуществлять контроль своих и чужих эмоций.

Результаты экспресс-опросника «Индекс толерантности» (Г.У. Солдатова, О.А. Кравцова, О.Е. Хухлаев, Л.А. Шайгерова) представлены на рисунке 3.

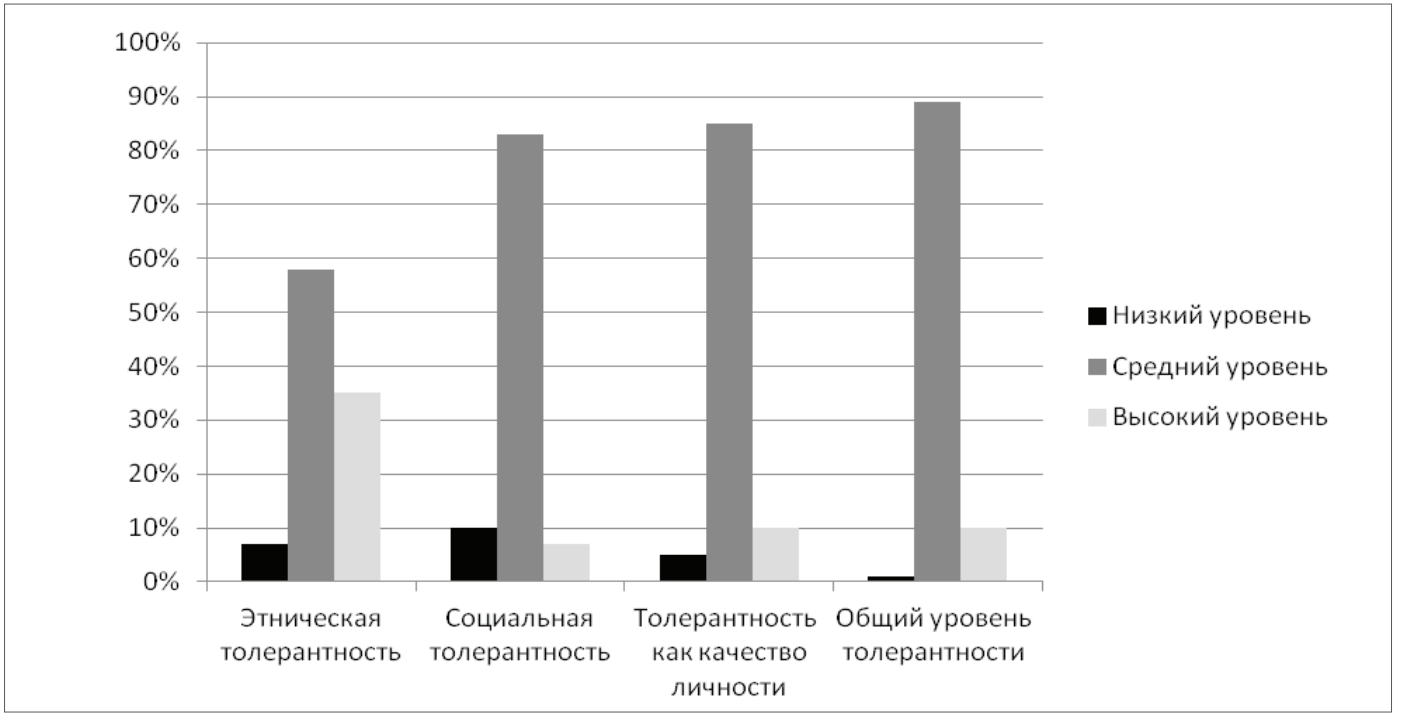

Рис. 3. Индекс толерантности, \%

Исходя из данных, представленных на рисунке 3, можно сказать, что в общем студенты толерантны в отношении других этнических и социальных групп.
Для проверки выдвинутой гипотезы использовался метод корреляционного анализа (К. Пирсон). Данные этого анализа представлены в таблице 1.

Таблица 1

Данные корреляционного анализа между шкалами толерантности с эмоциональным и социальным интеллектом

\begin{tabular}{|c|c|c|c|c|c|c|c|c|c|c|c|c|}
\hline \multirow[b]{2}{*}{ 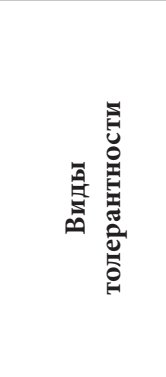 } & \multicolumn{12}{|c|}{ Виды эмоционального интеллекта } \\
\hline & 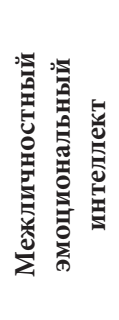 & 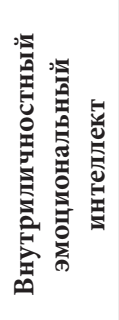 & 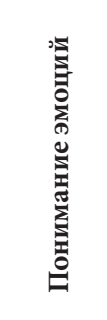 & 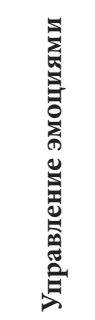 & 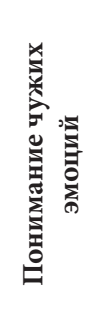 & 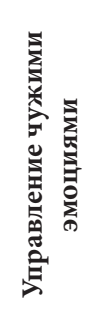 & 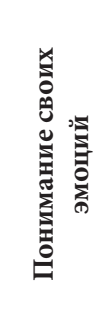 & 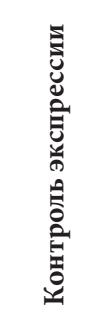 & 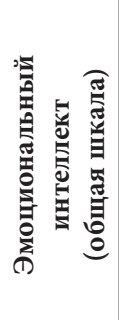 & 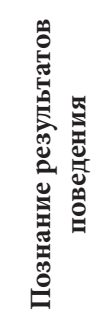 & 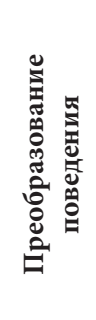 & 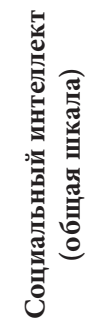 \\
\hline $\begin{array}{l}\text { Этническая } \\
\text { толерант- } \\
\text { ность }\end{array}$ & $0,225^{\star}$ & 0,112 & $0,238^{*}$ & 0,210 & 0,189 & $0,216^{*}$ & $0,220^{*}$ & 0,037 & $0,217^{\star}$ & $-0,092$ & 0,040 & 0,047 \\
\hline $\begin{array}{l}\text { Толерант- } \\
\text { ность, как } \\
\text { качество } \\
\text { личности }\end{array}$ & 0,166 & $0,244^{*}$ & $0,242^{*}$ & $0,232^{*}$ & 0,146 & 0,153 & $0,293^{* *}$ & $0,273^{\star}$ & $0,274^{*}$ & $0,262^{*}$ & $0,221^{*}$ & $0,139^{*}$ \\
\hline $\begin{array}{l}\text { Общий } \\
\text { уровень } \\
\text { толерант- } \\
\text { ности }\end{array}$ & $0,256^{*}$ & 0,168 & $0,294^{* *}$ & $0,264^{*}$ & $0,224^{*}$ & $0,237^{\star}$ & $0.292^{\star *}$ & 0,122 & $0,287^{\star *}$ & $0,287^{* *}$ & 0,110 & 0,108 \\
\hline
\end{tabular}

Примечание: ${ }^{*}-(p \leq 0,05),{ }^{* *}-(p \leq 0,01),{ }^{* *}-(p \leq 0,001)$ 
Анализ данных корреляционных связей между толерантностью и эмоциональным интеллектом показывает, что чем выше способность к пониманию эмоций других людей и управлению ими, тем сильнее выражены толерантное отношение человека к представителям других этнических групп и установки в сфере межкультурного общения. Чем выше способности к пониманию собственных эмоций и управлению ими, способности к пониманию эмоций других людей и управлению ими, тем сильнее развиты личностные качества, установки и убеждения, которые в большей степени определяют отношение человека к окружающему миру. Чем выше уровень развития эмоционального интеллекта, тем толерантнее человек во взаимоотношениях с окружающими его людьми.

Анализируя корреляционные связи между толерантностью и социальным интеллектом, мы видим, что чем сильнее развита способность предугадывать поведение людей, опираясь на понимание их чувств, намерений и мыслей, тем толерантнее является человек во взаимоотношениях с окружающими его людьми. То есть студенты, которые способны предугадывать дальнейшие поступки людей на основе анализа реальных ситуаций общения (семейного, делового, дружеского), предсказывать события, опирающиеся на понимание чувств, мыслей, намерений участников коммуникации, будут более толерантны во взаимоотношениях с окружающими людьми.

Чем выше развита способность понимания речевой экспрессии, тем сильнее развиты личностные качества, установки и взгляды, которые в большей степени определяют отношение человека к окружающему миру. То есть студенты, обладающие значительной чувствительностью к характеру и оттенкам человеческих взаимоотношений, умеют находить соответствующий тон общения с разными собеседниками в разных ситуациях, будут являться более толерантными во взаимоотношениях с окружающими.

Чем сильнее развита способность понимания языка невербального общения, умения прогнозировать реакции людей в заданных обстоятельствах, тем сильнее развиты личностные черты, установки и убеждения, которые в значительной степени определяют отношение человека к окружающему миру. То есть лица с высокоразвитым социальным интеллектом, обладающие открытостью, доброжелательностью, тактичностью во время общения, будут более толерантны в процессе коммуникации.

Таким образом, результаты эмпирического исследования свидетельствуют о том, что студенты, имеющие высокие показатели в области социального интеллекта, характеризуются такими личностными качествами, как открытость, доброжелательность, сердечность. Они способны извлекать максимум информации о поведении людей, успешно прогнозировать язык невербального общения, проявлять дальновидность в отношениях с другими, что способствует успешной социальной адаптации. Полученные данные свидетельствуют, что у большинства испытуемых преобладает средний уровень эмоционального интеллекта, это говорит о том, что данной выборке свойственно распознавать и понимать эмоции окружающих их людей, а также понимать эмоциональное состояние человека, основываясь на внешних проявлениях эмоций.

Анализ полученные данных по результатам изучения толерантности показал, что для студентов, которые принимали участие в исследовании, характерен средний уровень толерантности. Такие данные говорят о том, что данной выборке присуще сочетание как толерантных, так и интолерантных черт.

Анализируя корреляционные связи, можно сделать вывод, что уровень развития толерантности будет зависеть от того, как хорошо развиты у студента способности предугадывать поведение людей, понимания речевой экспрессии, а также умения прогнозировать реакции людей в заданных обстоятельствах. На уровень развития толерантности в студенческом возрасте оказывает влияние развитие эмоционального интеллекта, а именно понимание своих эмоций и эмоций окружающих людей, способности вызывать у других людей те или иные эмоции. Таким образом, анализ полученных данных позволяет делать выводы, что социальный и эмоциональный интеллект связан с толерантностью в студенческом возрасте. Результаты эмпирического исследования обозначили основные направления работы по формированию личностной компетентности профессионала.

\section{Библиографический список}

1. Савенков А. И. Социальный интеллект как проблема психологии одаренности и творчества // Психология. Журнал Высшей школы экономики. 2005. № 4. С. 94-101.

2. Гилфорд Дж. Три стороны интеллекта // Психология мышления. М.: Прогресс, 1965. 14 с. 
3. Лунева О. В. История исследования социального интеллекта // Знание. Понимание. Умение. 2008. № 4. C. $177-182$.

4. Ушаков Д. В. Социальный и эмоциональный интеллект: теоретические подходы и методы измерения // Вести. Рос. гуманитар. науч. фонда. 2005. № 4. С. 131-139.

5. Асмолов А. Г. Толерантность: различные парадигмы анализа // Толерантность в общественном сознании России. М., 1998. 231 с.

6. Карпов А. В. Психология эмоционального интеллекта: теория, диагностика, практика: монография. Ярославль: ЯрГУ, 2008. 344 с.

7. Гоулман Д. Эмоциональный интеллект. Москва: АСТ ; Владимир: ВКТ, 2011. 478 с.

8. Карпов А. В., Петровская А. С. Проблемы эмоционального интеллекта в парадигме современного метакогнитивизма // Вестник интегративной психологии. 2006. Вып. 4. С. 42-47.

9. Практический интеллект. Сер.: Мастера психологии / Р. Дж. Стернберг и др. СПб.: Питер, 2002. 272 с.

10. Люсин Д. В. Современные представления об эмоциональном интеллекте. М.: Институт психологии РАН, 2004. С. 29-36.

11. Бондырева С. К., Колесов Д. В. Толерантность (введение в проблему). М.: Московский психолого-социальный университет ; Воронеж: МОДЭК, 2003. 240 с.

12. Московичи С. Век толп. М.: Центр психологии и психотерапии, 1998. 480 с.

13. Маслоу А. Мотивация и личность. СПб.: Евразия, 1999. 572 с.

14. Роджерс К. Взгляд на психотерапию. Становление человека. М.: Прогресс. 1994. 480 с.

15. Ананьев Б. Г. Человек как предмет познания психологии. СПб.: Питер, 2001. 288 с.

16. Асмолов А. Г. Толерантность - культура XXI века // Век толерантности. 2004. № 7. С. 4-8.

17. Психодиагностика толерантности личности / под ред. Г. У. Солдатовой, Л. А. Шайгеровой. М.: Смысл, 2008. $172 \mathrm{c}$.

18. Фетискин Н. П. Социально-психологическая диагностика развития личности и малых групп. М.: Изд-во Института психотерапии. 2002. 490 с.

19. Люсин Д. В. Новая методика для измерения эмоционального интеллекта // Психологическая диагностика. 2006. № 4. С. 3-22. 